\title{
Utilização de adesivos de cianoacrilatos em suturas de pele
}

\author{
Utilization of cyanoacrylates adhesives in skin suture
}

\author{
Chreichi Lopes De Oliveira ${ }^{1}$ \\ Carlos Henrique Marques \\ DOS SANTOS ${ }^{2}$ \\ Fernando Márcio Matos \\ BEZERRA $^{3}$ \\ Marcelo Matos Bezerra ${ }^{4}$ \\ LÊNIN DE LIMA RodRigues ${ }^{5}$
}

Trabalho realizado na Universidade Federal de Mato Grosso do Sul, Campo Grande, MS, Brasil.

Artigo submetido no SGP (Sistema de Gestão de Publicações) da RBCP.

Artigo recebido: 21/5/2009 Artigo aceito: $14 / 8 / 2009$

\begin{abstract}
RESUMO
Introdução: Cianoacrilatos (CA) são monômeros líquidos que se polimerizam quando aplicados à pele, formando uma forte cola. Aplicável em várias áreas médicas e resultados promissores em salas de emergência. Discussão: A maioria dos estudos revisados demonstra resultados comparáveis desses adesivos aos métodos tradicionais. Seu uso está indicado para lesões limpas, após hemostasia adequada, em locais de baixa tensão e não úmidos, especialmente em pessoas jovens. Algumas vantagens são a redução do tempo operatório proporcional ao tamanho da sutura, fácil aplicação, sem uso de anestesia, não necessidade de remoção, menor risco de acidente perfurocortante, indolor e provável ação antimicrobiana de alguns CA. Como desvantagens há o alto custo do adesivo, menor resistência à tensão e à umidade, sensação de queimação no local da aplicação, aderência do adesivo a roupas e contato com o interior da lesão. Complicações relatadas são maior índice de deiscência de suturas, segundo apenas um autor, e pior aproximação das bordas da lesão. Conclusão: Quando bem indicados, os CA são uma boa alternativa aos fios de sutura, com resultados estéticos e funcionais comparáveis aos métodos tradicionais e risco de complicações aceitáveis. Há necessidade de mais ensaios clínicos com uso de colas de menor custo, para demonstrar sua segurança e aplicabilidade na prática médica, principalmente em países em desenvolvimento, como o Brasil.
\end{abstract}

Descritores: Cianoacrilatos. Técnicas de sutura. Adesivos teciduais. Pele.

\section{SUMMARY}

Introduction: Cyanoacrylates are liquid monomers that polymerizes, resulting in a strong hold when applied to skin. Applicable in lots of areas in Medicine and promising results in emergency rooms. Discussion: The majority of the revised studies about these adhesives demonstrate results comparable to the traditional methods of suture. It is indicated for clean injuries, after adequate hemostasia, in not humid places and low tension and, especially in young people. Some advantages are the decreasing of surgery time proportionally to the size of the suture, easy application, anesthesia not needed, do not require removal, minor risk of needle sticks, painless and probably biocide activity of some CA. The disadvantages are the high cost of the adhesive, minor resistance to tension and humidity, sensation of burn in the application area, tack of the adhesive to the clothes and contact with the interior of the injury. Related complications are the higher index of dehiscence of sutures according to only one author and worse approach of the edges of the injury. Conclusion: When correctly indicated CA are a good alternative to suture wires and have aesthetic and functional results equivalent to traditional methods and acceptable risk of complications. More clinical assays with low cost glue are necessary to demonstrate its security and applicability in the practical, mainly in developing countries as Brazil.

Descriptors: Cyanoacrylates. Suture techniques. Tissue adhesives. Skin.

1. Cirurgiã Plástica; Membro Associado da Sociedade Brasileira de Cirurgia Plástica (SBCP).

2. Doutor em Medicina; Professor Assistente de Clínica Cirúrgica pela Universidade Federal de Mato Grosso do Sul.

3. Graduando em Medicina pela Universidade Federal de Mato Grosso do Sul.

4. Médico cirurgião geral; Residente em Cirurgia Plástica pela Universidade Federal de Minas Gerais.

5. Médico; Residente em Cirurgia Geral pelo Hospital Regional de Mato Grosso do Sul. 


\section{INTRODUÇÃO}

Cianoacrilatos (CA) são monômeros líquidos que polimerizam em uma reação exotérmica quando em contato com fluidos ou substâncias básicas, formando uma forte cola quando aplicada à pele. O calor produzido pela reação é inversamente proporcional ao tamanho do grupo alquil da molécula ${ }^{1}$. Os adesivos à base de CA foram descobertos em 1949 e dez anos após foram utilizados em procedimentos cirúrgicos ${ }^{2}$.

Toda cola de CA eventualmente degrada-se em formaldeído e cianoacetato. Apesar da sabida toxidade do formaldeído, nenhuma degradação significante ocorre antes do produto ter se desprendido da pele, não contribuindo para a toxidade em seu uso tópico ${ }^{3}$.

Os primeiros adesivos eram compostos de moléculas com cadeias laterais curtas (Metil e Etilcianoacrilatos), mais sujeitos a quebras, restringindo seu uso a situações de baixa tensão ${ }^{4}$. Com o uso de cadeias alquil maiores, a resistência à tensão foi aumentada e a toxidade foi significantemente reduzida, pois a degradação é retardada, limitando o acúmulo de produtos tóxicos. Por esse motivo, o N-butil-2-cianoacrilato (Indermil®) e o 2-octilcianoacrilato (Dermabond ${ }^{\circledR}$ ), que possuem cadeias maiores, são os mais utilizados em Medicina ${ }^{1}$.

O uso dessas colas é relatado nos mais variados campos da Medicina e ciências biomédicas, tais como odontologia, ortopedia, cirurgia plástica, videocirurgia, mastologia, cirurgia torácica, oftalmologia, cirurgia de cabeça e pescoço e, com resultados promissores em suturas de emergência $a^{1,3-12}$. Há um notório caso brasileiro do uso bem sucedido em cirurgia cardíaca de um cianoacrilato de uso doméstico (super bonder) relatado em uma revista não científica de grande circulação nacional ${ }^{13}$.

\section{MÉTODO}

Por meio da base de dados MEDLINE/PubMed, de outubro de 2008 até o dia 13 de janeiro de 2009, foram pesquisados artigos da literatura médica da língua inglesa, que relataram a utilização de colas de cianoacrilato para síntese de pele. As palavras-chave cyanoacrylates, suture techniques, tissue adhesives e skin foram usadas em combinação na pesquisa. Foram selecionados dezesseis trabalhos, independente da data que foram publicados, haja vista a pouca quantidade de artigos sobre o tema. Foram incluídos também quatro artigos sobre estudos experimentais e análise microbiológica dos cianoacrilatos para melhor embasar a revisão. Foram excluídos artigos duplicados ou sem relevância com o tema.

\section{DISCUSSÃO}

A grande maioria dos estudos revisados tem demonstrado bons resultados com o uso de colas à base de cianoacrilatos para sutura de pele em humanos, comparáveis aos métodos tradicionais de sutura ${ }^{1,3,5,7-12,14-16}$. Porém há ainda controvérsias quanto a sua utilização em algumas situações específicas, Ridgway et al. ${ }^{4}$, em seu ensaio, relatam a superioridade dos grampos de sutura para fechamento de cervicotomias em relação às colas teciduais e à sutura tradicional.

$\mathrm{O}$ uso dos adesivos teciduais deve ser limitado a lesões não infectadas ou contaminadas, de baixa tensão, em feridas cirúrgicas ou traumáticas, desde que a coaptação das bordas seja fácil ${ }^{3}$ e a hemostasia adequada ${ }^{11}$. Está especialmente indicado em regiões de pele frágil, pois não provoca a lesão ou isquemia, como pode ocorrer com o uso de fios ${ }^{3}$.

As vantagens dos cianoacrilatos em relação às suturas convencionais são diversas, dentre elas destaca-se a redução do tempo operatório ${ }^{7-11}$, que seria diretamente proporcional ao tamanho da ferida a ser fechada ${ }^{1,3,11}$. Segundo Bozkurt e Saydam $^{1}$, o uso de adesivos seria quinze vezes mais rápido do que a confecção de sutura com fio em cirurgias de cabeça e pescoço. Apenas Ridgway et al. ${ }^{4}$ obtiveram maior tempo cirúrgico com uso de adesivos teciduais.

Alguns estudos apontam propriedade antimicrobiana dos CA in vivo e in vitro, principalmente contra bactérias gram positivas $^{3,11,17}$. Há um destaque para o etil-cianoacrilato (super bonder $\left.{ }^{\circledR}\right)$, que teria ação efetiva contra Staphylococcus e Streptococci e bactérias gram negativas, como Escherichia coli e Escherichia faecalis ${ }^{18}$, mas não contra Staphylococcus aureus e Pseudomonas aeruginosa ${ }^{19}$. Na prática cirúrgica, dois autores não observaram qualquer diminuição da taxa geral de infecção com o uso de adesivos teciduais ${ }^{9,16}$, porém Ridgway et al. ${ }^{4}$ relatam tendência à redução de infecção do sítio operatório com uso de colas.

A técnica de aplicação dos CA para uso em suturas é indolor, de fácil aprendizado e não requer instrumentos especiais ou anestesia ${ }^{3,10,14}$. O adesivo se desprende com cinco a dez dias, não sendo necessários procedimentos para remoção, que poderiam ser dolorosos e traumatizantes, principalmente para crianças, além de prevenir o deslocamento de pacientes, principalmente os que residem em regiões distantes ${ }^{3,11}$. Singer et al. ${ }^{3}$ relatam ainda menor curva de aprendizagem para aplicação das colas teciduais em relação à sutura convencional, além de ser um procedimento mais seguro para a equipe cirúrgica, pois há redução do risco de acidentes perfurantes com agulhas.

Os CA quando aderidos à pele formam uma barreira de proteção contra infecções, permitindo a lavagem do local pouco tempo após a cirurgia, gerando qualidade de vida para o paciente ${ }^{3,8,11}$. O seu uso dispensa a utilização de curativos e de produtos tópicos sobre a ferida ${ }^{3,11,14}$ e há facilidade de 
sua remoção com o uso de água e sabão ${ }^{9}$. Ridgway et al. ${ }^{4}$ tiveram um caso de deiscência de sutura pelo uso inadvertido de curativos sobre a película adesiva.

A somatória de todas as vantagens da utilização dos CA citadas determina, segundo alguns autores, economia em relação à técnica convencional, apesar do custo do produto isoladamente ser mais elevado do que a maioria dos fios cirúrgicos. Isso se deve à não necessidade de curativos, redução dos instrumentos de sutura, do tempo de uso de centros cirúrgicos e de serviço de médicos e auxiliares ${ }^{7,9-11}$. Apenas um autor não concorda, porém não considera outros custos além do adesivo ${ }^{1}$.

Segundo Ridgway et al. ${ }^{4}$, a deiscência de suturas está levemente aumentada com o uso de CA em relação aos fios cirúrgicos, fato não observado por outros autores, que não consideram aumento dessa complicação com significância estatística $^{1,10-12,16}$. Os resultados estéticos, avaliados por meio de escala visual analógica, foram comparáveis aos da sutura convencional ${ }^{4,7,9-11,15}$, porém Rimmer et al. ${ }^{8}$ referem que a aparência da cicatriz depende da acurácia da aplicação da cola e da tensão do local de aplicação. Handschel et al. ${ }^{12}$ ressaltam que melhores aspectos cosméticos são obtidos com suturas com fio quando os pacientes são jovens (menores de 25 anos).

Há desvantagens em relação ao uso dos CA, tais como alto custo do adesivo ${ }^{1}$, menor resistência à tensão e à umidade ${ }^{3}$. Singer et al. ${ }^{3}$, em sua revisão, relatam algumas "armadilhas" do uso de colas teciduais: sensação de queimação no local da aplicação, possibilidade da cola escorrer, contato com os olhos, aderência do adesivo a roupas e contato com o interior da lesão. Portanto, um dos cuidados pós-operatórios é manter as feridas secas e limpas, evitando a escovação com sabão.

Handschel et al. ${ }^{12}$ concluíram, em seu ensaio com 45 pacientes, que a profundidade das cicatrizes resultantes do uso de CA é significantemente maior quando comparada aos fios de sutura, resultado de menor aproximação propiciada pelo adesivo.

A maioria dos autores realizou o preparo da ferida por meio do fechamento criterioso do subcutâneo, evitando espaço morto e reduzindo a tensão sobre a ferida antes da

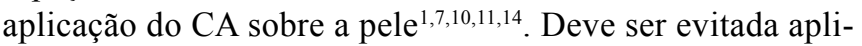
cação em plantas dos pés, palmas das mãos e locais úmidos como mucosas ${ }^{3}$.

Em sua revisão, Singer et al. ${ }^{3}$ sugerem a utilização sinérgica de fitas adesivas porosas para facilitar a coaptação das bordas e reforçar a sutura. D'Assumpção ${ }^{5}$ utilizou hastes com ponta de algodão (cotonetes ${ }^{\circledR}$ ) para espalhar a cola sobre a pele de modo a formar uma fina película de $15 \mathrm{~mm}$ de largura. Outros autores utilizaram aplicadores próprios das colas de uso cirúrgico, seguindo as recomendações dos fabricantes ${ }^{4,11,12}$. Deve haver especial cuidado para evitar que a substância penetre na ferida ${ }^{10-12}$.

Uma alternativa aos altos preços dos CA disponíveis no mercado é o uso de fitas adesivas para suturas em locais de baixa tensão, por serem de baixo preço, fácil aplicação e remoção ${ }^{3}$. Outra opção é utilizar CA para uso doméstico como o super bonder ${ }^{\circledR}$ (etil-cianoacrilato), segundo D'Assumpção ${ }^{5}$, que realizou um ensaio com 200 pacientes utilizando essa substância em síntese de pele em mamoplastias e abdominoplastias. Em seu estudo não foi observada qualquer diferença em relação às complicações e resultado estético. Outros autores comprovaram a esterilidade e efeito antibacteriano dessa cola ${ }^{18,19}$, porém em um estudo experimental com animais a $o$ Three Bond ${ }^{\circledR}$ (alfa cianoacrilado) apresentou maior biocompatibilidade, comparável à água destilada $^{20}$. Enquanto outro afirma que o etil-cianoacrilato obteve os piores resultados em relação à inflamação quando comparados ao fio de nylon ${ }^{21}$.

\section{CONCLUSÃO}

Os CA são uma opção interessante à sutura tradicional de pele, indicados para cirurgias limpas, em locais secos e sujeitos à baixa força de tensão, pois, nessas condições, seus resultados estéticos e complicações são comparáveis ao uso de fios cirúrgicos, com a vantagem de serem de rápida aplicação e não necessitarem de procedimento de remoção. No entanto, devido ao alto custo, essas substâncias estão longe da realidade da maioria dos hospitais brasileiros, tornandose necessária a realização de mais ensaios clínicos com uso de colas alternativas de menor custo, para demonstrar sua segurança e aplicabilidade na prática médica.

\section{REFERÊNCIAS}

1. Bozkurt MK, Saydam L. The use of cyanoacrylates for wound closure in head and neck surgery. Eur Arch Otorhinolaryngol. 2008;265(3):331-5.

2. Coover HN, Joyner FB, Sheerer NH, Wicker TH. Chemistry and performance of cyanoacrylate adhesive. Special Tech Papers. 1959;5:4137. apud Bozkurt MK, Saydam L. The use of cyanoacrylates for wound closure in head and neck surgery. Eur Arch Otorhinolaryngol. 2008;265(3):331-5

3. Singer AJ, Quinn JV, Hollander JE. The cyanoacrylate topical skin adhesives. Am J Emerg Med. 2008;26(4):490-6.

4. Ridgway DM, Mahmood F, Moore L, Bramley D, Moore PJ. A blinded, randomized, controlled trial of stapled versus tissue glue closure of neck surgery incisions. Ann R Coll Surg Engl. 2007;89(3):242-6.

5. D'Assumpção EA. Cola de cianoacrilato de baixo custo em cirurgia plástica. Rev Soc Bras Cir Plást. 2008;23(1):22-5.

6. Saska S, Roslindo EB, Bolini PDA, Minarelli-Gaspar AM. Uso do adesivo à base de etil-cianoacrilato na reparação óssea. Rev Bras Ortop. 2004;39(8):461-7.

7. Nahas FX, Solia D, Ferreira LM, Novo NF. The use of tissue adhesive for skin closure in body contouring surgery. Aesthetic Plast Surg. 2004;28(3):165-9.

8. Rimmer J, Singh A, Banwell P, Clarke PM, Rhys Evans P. The use of octyl-2-cyanoacrylate (Dermabond) tissue adhesive for skin closure in head and neck surgery. Ann R Coll Surg Engl. 2006;88(4):412-3.

9. Shamiyeh A, Schrenk P, Stelzer T, Wayand WU. Prospective randomized blind controlled trial comparing sutures, tape, and octylcyano- 
acrylate tissue adhesive for skin closure after phlebectomy. Dermatol Surg. 2001;27(10):877-80.

10. Sebesta MJ, Bishoff JT. Octylcyanoacrylate skin closure in laparoscopy. J Endourol. 2003;17(10):899-903.

11. Gennari R, Rotmensz N, Ballardini B, Scevola S, Perego E, Zanini V, et al. A prospective, randomized, controlled clinical trial of tissue adhesive (2-octylcyanoacrylate) versus standard wound closure in breast surgery. Surgery. 2004;136(3):593-9.

12. Handschel JG, Depprich RA, Dirksen D, Runte C, Zimmermann A, Kübler NR. A prospective comparison of octyl-2-cyanoacrylate and suture in standardized facial wounds. Int J Oral Maxillofac Surg. 2006;35(4):318-23.

13. Mezarobba G. Coração remendado. Revista Veja: Ed. Abril. 11 de março de 1998.

14. Blondeel PN, Murphy JW, Debrosse D, Nix JC $3^{\text {rd }}$, Puls LE, Theodore $\mathrm{N}$, et al. Closure of long surgical incisions with a new formulation of 2-octylcyanoacrylate tissue adhesive versus commercially available methods. Am J Surg. 2004;188(3):307-13.

15. Souza SC, Oliveira WL, Soares DF, Briglia CH, Athanázio PR, Cerqueira $\mathrm{MD}$, et al. Comparative study of suture and cyanoacrylates in skin closure of rats. Acta Cir Bras. 2007;22(4):309-16.

16. Coulthard P, Worthington H, Esposito M, Elst M, Waes OJ. Tissue adhesives for closure of surgical incisions. Cochrane Database Syst Rev. 2004;(2):CD004287.

17. Gueiros VA, Borges APB, Silva JCP, Duarte TS, Franco KL. Utilization of the methyl-2-cyanoacrylate adhesive and the nylon suture in surgical skin wounds of dogs and cats. Ciência Rural. 2001;31(2).

18. Almeida Manzano RP, Naufal SC, Hida RY, Guarnieri LO, NishiwakiDantas MC. Antibacterial analysis in vitro of ethyl-cyanoacrylate against ocular pathogens. Cornea. 2006;25(3):350-1.

19. Ueda EL, Hofling-Lima AL, Sousa LB, Tongu MS, Yu MCZ, Lima AAS. Avaliação de um cianoacrilato quanto à esterilidade e atividade biocida. Arq Bras Oftalmol. 2004;67(3):397-400.

20. Moretti Neto RT, Mello I, Moretti AB, Robazza CR, Pereira AA. In vivo qualitative analysis of the biocompatibility of different cyanoacrylatebased adhesives. Braz Oral Res. 2008;22(1):43-7.

21. Borba CC, Neto ER, Val RLR, Borba JCO, Soufen MA, Neto AF, ET al. Uso do cianoacrilato na síntese da pele de ratos: trabalho de pesquisa experimental. Acta Cirúrgica Brasileira [serial online] 2000;15(1). URL: http:www.scielo.br/acb.

Correspondência para:

Chreichi Lopes de Oliveira

Av. Rouxinol, 762 - apto 36 - Moema - São Paulo, SP, Brasil - CEP 04516-001

E-mail: chreichi@yahoo.com.br 